\title{
Study on Influencing Factors of Travel Intention after Disaster: a Case Study of the 8 August Jiuzhaigou Earthquake
}

\author{
Yue $\mathrm{Li}^{1, \mathrm{a}^{*}}$, Sha Li ${ }^{1, \mathrm{~b}}$, Baichun Ma ${ }^{1, \mathrm{c}}$ and Yuzhi Liu${ }^{1, \mathrm{~d}}$ \\ ${ }^{1}$ Tourism School, Sichuan Agricultural University, Dujiangyan, China \\ a26005476@qq.com, b554206464@qq.com, c1049068104@qq.com, d948175153@qq.com \\ * The corresponding author
}

Keywords: Travel Intention; Natural Disasters; Risk Perception; Destination Image Perception; Familiarity

\begin{abstract}
The Jiuzhaigou M7 earthquake damaged the Aba's tourism economy. Almost one year later, Aba's tourism economy hasn't recovered to the pre-earthquake level, it is necessary to explore the main factors affecting travel intention after disasters, and then provide more accurate theoretical guidance for the market revitalization. Taking the 8th August Jiuzhaigou earthquake (2017) as an example, this paper uses SPSS and Mplus to conduct factor analysis, structural equating modeling and so on, in order to analyze the main factors of travel intention after serious earthquake through risk perception, destination image perception and familiarity. The results indicate that:(1) There is a significant negative relationship between risk perception and travel intention;(2) Destination image perception and familiarity have no significant relationship with travel intention;(3) However, the three dimensions of destination image perception are positively related to travel intention.
\end{abstract}

\section{Introduction}

The Jiuzhaigou earthquake (magnitude of 7.0 , occurred on 8 August 2017) damaged the Aba's tourism economy and some scenic spots in Jiuzhaigou. The secondary and derivative disasters seriously affected the tourists' travel intention. In May 2018, Aba's tourism economy still not recovered, the total tourism revenue decreased by $40.29 \%$ over the same period in 2017 . In recent years there have been frequent natural disasters around the world. Although the disaster area has taken positive strategy to recovery the tourist market, it still slow and restricts the development of tourism. It is necessary to know the factors to travel intention, so that provide marketing strategy theoretical reference.

Recent years, many researches on post-disaster travel destination management have emerged in academic circles. Liu Shiming studied the reasons of tourists loss after Wenchuan earthquake from five dimensions, which provided a multi-angle consideration for tourists loss after the disaster[1]. However, the study ignored the impact of destination image perception on travel intention. Li Yue explored the impact of destination image perception and destination familiarity on travel intention from risk perception, and included the impact of destination image perception and destination familiarity on travel intention[2]. A model of post-disaster travel intention is constructed. However, Li Yue's model is based on the Wenchuan earthquake. Whether the model can be applied to Jiuzhaigou earthquake still needs further demonstration. Taking the 8.8 Jiuzhaigou earthquake as an example, using Li Yue's model for post-disaster travel intention as a reference, this paper analyzes the main factors influencing travel intention from three angles: risk perception, destination image perception and familiarity. The purpose is further demonstrating the application of the model in different earthquake, and to provide a theoretical reference for the recovery of tourism market after the Jiuzhaigou earthquake.

\section{Literature Review}

Risk perception. Sitkin and Weingart define risk as " the existence of certainty in possible important results or undesired results in decision - making"[3].Huang chongfu, Liu anlin and Wang 
Ye gave the basic definition of natural disaster risk, " future adverse event scenarios caused by natural events or forces". They believe that past and present events cannot be called risks[4]. Bauer goes beyond psychology to introduce risk perception into consumer behavior research. He believes that any consumption of the consumer may produce inconsistent results with their expectations [5].

Destination Image Perception. Travel destination image is one of the important factors that affect tourists' choice of $\mathrm{c}$ destination. Michael Grosspietsch pointed out that perceived image is the perception and image of potential and real tourists to the travel destination[6]. Baloglu and other scholars divided tourists' perceived image into perception image and emotional image[7].

Familiarity. Freedman's Social Psychology put "familiarity" firstly in 1984[8]. Maestro et al regard travel destination familiarity as a process of information evaluation[9]. Cheng Wei and Sui Lina pointed out that familiarity will significantly affect various dimensions of perception image and emotional image[10]. Gao Jing et al pointed out that under the background of China, the higher familiarity degree, the higher satisfaction and loyalty of tourists to the destination[11].

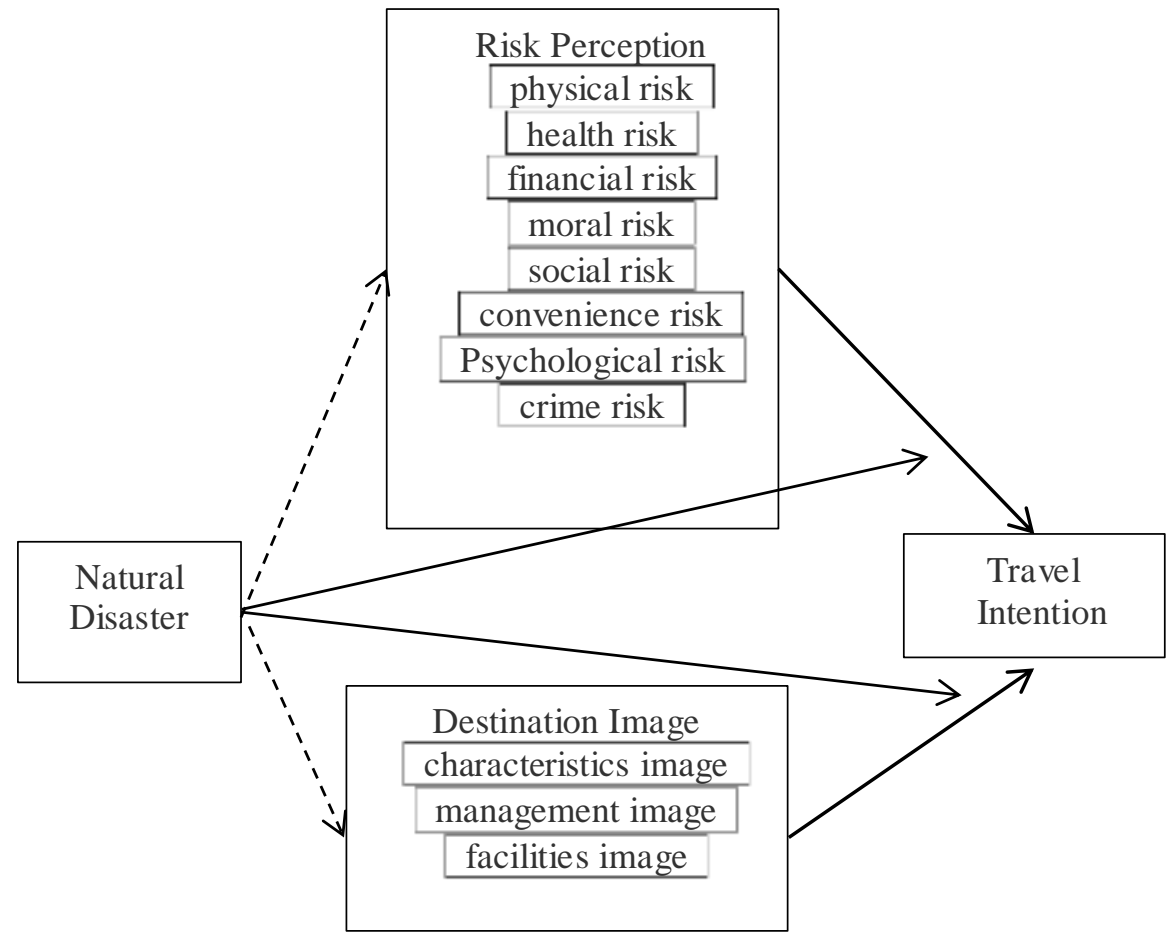

Figure 1. Finite Relationship between post-disaster risk perception and destination image perception and travel intention

Comprehensive Influence Model of Post-disaster Risk Perception, Destination Image Perception and Familiarity on Travel Intention. Yavas first studied the relationship between risk perception and international travel decision making[12]. Yang Huihui et al. proposed that in the process of purchase decision, tourists' willingness to purchase reflects the tourists' purchase decision and the tourists' final decision[13]. Therefore, the travel decision is expressed by travel intention. Up to now, destination image perception plays a very important role in various travel decision making models $[14,15]$. Yang Jie et al. showed that familiarity had the greatest influence on travel intention in the model of travel image perception behavior[16].And the model is shown in Fig. 1.

\section{Research hypothesis.}

$\mathrm{H} 1$ : the risk perception of potential tourists is negatively correlated with travel intention.

H1a: potential tourists' physical risk perception is negatively correlated with travel intention.

$\mathrm{H} 1 \mathrm{~b}$ : potential tourists' health risk perception is negatively correlated with travel intention.

H1c: potential tourists' financial risk perception is negatively correlated with travel intention.

H1d: potential tourists' moral risk perception is negatively correlated with travel intention.

H1e: potential tourists' social risk perception is negatively correlated with travel intention.

H1f: potential tourists' convenience risk perception is negatively correlated with travel intention. 
H1g: potential tourists' psychological risk perception is negatively correlated with travel intention.

H1h: potential tourists' crime risk perception is negatively correlated with travel intention.

$\mathrm{H} 2$ : potential tourists' destination image perception is positive correlated with travel intention.

H2a: potential tourists' destination characteristics image perception is positive correlated with travel intention.

H2b: potential tourists' destination management image perception is positive correlated with travel intention.

H2c: potential tourists' destination facilities image perception is positive correlated with travel intention.

H3: potential tourists' familiarity to destination is negatively correlated with the post-disaster risk perception.

H4: potential tourists' familiarity to destination is positively correlated with destination image perception.

H5: potential tourists' familiarity to destination is positively correlated with travel intention.

\section{Questionnaire survey}

Data Sources. This paper adopts convenience sampling. Based on the snowball method and quota method. A total of 626 questionnaires were obtained, including 616 valid questionnaires. In the statistical analysis and the representation of these scores follows: 1-5 = very disagree-very agree.

Data Analysis.

(1)Reliability analysis. About 32 topics of post-disaster risk perception, the Alpha coefficient is 0.923 , each topic's CITC is more than 0.4. About 21 topics of destination image perception, the Alpha coefficient is 0.939 , each topic's CITC is more than 0.4. About 5 subjects of familiarity, the Alpha coefficient is 0.721 . However, the CITC of t57 is 0.152 , which is less than 0.4, the Alpha coefficient would increase from 0.721 to 0.783 when deleting t57. So it's need to delete t57. About 3 topics of travel intention, the Alpha coefficient is0.743, and the CITC is more than 0.4.

(2)Exploratory factor analysis. Use SPSS to carry out exploratory factor analysis on each variable. Principal component analysis method was used to extract common factors. Variance maximization method was used to carry out factor rotation. And the number of factors was determined according to the principle that the characteristic root was greater than 1 .

About 32 topics of risk perception. 8 factors were extracted from the system, and the cumulative variance interpretation rate is $74.368 \%$. We named them A: physical risk, B: health risk, C: financial risk, D: moral risk, E: social risk, FG: convenience risk, HI: psychological risk, and J: crime risk.

About 21 topics of destination image perception. 4 factors were extracted from the system, and the cumulative variance interpretation rate is $70.473 \%$. We named them $\mathrm{MN}$ : destination facilities image, $\mathrm{P}$ : destination management image, $\mathrm{K}$ : destination characteristic image, and L: destination activity image. Compared with the original hypothesis, this result increased the activity image of the destination. So increasing the hypothesis:

$\mathrm{H} 2 \mathrm{~d}$ : potential tourists' destination activity perception is positive correlated with travel intention.

About 3 topics of familiarity. A factor was extracted and the interpretation rate of cumulative variance was $60.899 \%$. The factor load of all the items in the scale is greater than 0.7 , which indicates that all of them had strong correlation with common factors.

About 3 topics of travel intention. A factor was extracted and the cumulative variance interpretation rate was $66.209 \%$. The factor load of all the items in the scale was greater than 0.7 , which indicated that all of them have strong correlation with common factors.

(3)confirmatory factor analysis. In order to verify the factor structure of each questionnaire, Mplus was used for confirmatory factor analysis. Considering that some variables were not strictly normal distribution, MLR is used to estimate the variables.

Through analysis, the standardized factor load of all items of the 4 scales was more than 0.5 , and most of them were more than 0.7 . The CR of all variables was more than 0.7 , and AVE was more than 0.5 except familiarity $(0.485)$ and travel intention $(0.498)$. 
(4)second-order model confirmatory factor analysis: The second-order factor model was constructed for risk perception, destination image perception. The results showed that the fitting index of the second-order factor model of risk perception and destination image perception was basically up to standard, and the CFI and TLI of the risk perception were slightly worse, indicating that the second-order model was basically acceptable. In the second-order factor model of risk perception and destination image perception, the load of all the first order factors was greater than 0.5 , and the combined reliability CR was greater than 0.8. The AVE of destination image perception is greater than 0.5 , but the AVE of tourist risk perception was less than 0.5 .

\section{Study Result}

Socio-demographic Characteristics. In terms of gender, female participants is slightly higher $(51.6 \%)$; the largest number of participants is $18-25$ years-old(74\%); $71.9 \%$ of the participants are university or undergraduate. As occupation, participants were mainly composed of students $(60.6 \%)$, while participants with an annual income of less than 20 thousand accounted for $62.0 \%$.

\section{Results and Validation of Higher-Order Factor Models.}

Table 1 Path test and hypothesis test results of high order factor model

\begin{tabular}{ccccccc}
\hline \multicolumn{2}{c}{ Original hypothesis } & $\begin{array}{c}\text { path } \\
\text { coefficient }\end{array}$ & $\begin{array}{c}\text { standardized } \\
\text { path coefficient }\end{array}$ & value & P & conclusion \\
\hline Travel intention $\leftarrow$ Risk perception & -0.307 & -0.136 & -2.333 & 0.02 & support \\
Travel intention $\leftarrow$ Destination image & 0.061 & 0.048 & 0.455 & 0.649 & nonsupport \\
Risk perception $\longleftarrow$ & familiarity & -0.012 & -0.028 & -0.547 & 0.584 & nonsupport \\
Destination image $\longleftarrow$ & familiarity & 0.644 & 0.829 & 28.832 & 0 & support \\
Travel intention $\longleftarrow$ & familiarity & 0.129 & 0.13 & 1.147 & 0.251 & nonsupport \\
\hline
\end{tabular}

\section{Results and Verification of low order Factor Model.}

Table 2 Path test and hypothesis test results of high order factor model

\begin{tabular}{|c|c|c|c|c|c|c|}
\hline \multicolumn{2}{|c|}{ Original hypothesis } & \multirow{2}{*}{$\begin{array}{c}\text { path } \\
\text { coefficient }\end{array}$} & \multirow{2}{*}{$\begin{array}{c}\begin{array}{c}\text { standardize } \\
\text { d path } \\
\text { coefficient }\end{array} \\
-0.162\end{array}$} & \multirow{2}{*}{$\begin{array}{c}\begin{array}{c}\mathrm{T} \\
\text { value }\end{array} \\
-2.784\end{array}$} & \multirow{2}{*}{$\begin{array}{c}\mathrm{P} \\
0.005\end{array}$} & \multirow{2}{*}{$\frac{\text { conclusion }}{\text { support }}$} \\
\hline travel intention & Physical risk & & & & & \\
\hline travel intention $\longleftarrow$ & Health risk & -0.11 & -0.128 & -2.287 & 0.022 & support \\
\hline travel intention $\longleftarrow$ & Finance risk & -0.095 & -0.133 & -2.499 & 0.012 & support \\
\hline travel intention $\longleftarrow$ & Social risk & 0.002 & 0.002 & 0.043 & 0.966 & nonsupport \\
\hline travel intention $\longleftarrow$ & Moral risk & -0.049 & -0.080 & -1.119 & 0.263 & nonsupport \\
\hline travel intention $\longleftarrow$ & Convenience risk & -0.059 & -0.073 & -1.341 & 0.180 & nonsupport \\
\hline travel intention $\longleftarrow$ & Psychological risk & -0.073 & -0.096 & -1.760 & 0.078 & nonsupport \\
\hline travel intention $\longleftarrow$ & Crime risk & -0.107 & -0.121 & -2.258 & 0.024 & support \\
\hline travel intention & $\begin{array}{l}\text { Destination } \\
\text { characteristics image }\end{array}$ & 0.110 & 0.148 & 2.878 & 0.004 & support \\
\hline travel intention & $\begin{array}{c}\text { Destination } \\
\text { Activities image }\end{array}$ & 0.094 & 0.128 & 2.244 & 0.025 & support \\
\hline travel intention & $\begin{array}{c}\text { Destination } \\
\text { Facilities image }\end{array}$ & 0.068 & 0.101 & 1.650 & 0.099 & nonsupport \\
\hline travel intention $\leftarrow$ & $\begin{array}{c}\text { Destination } \\
\text { management image }\end{array}$ & 0.114 & 0.167 & 2.932 & 0.003 & support \\
\hline
\end{tabular}

Discussion. Each dimension of post-disaster risk perception and destination image perception has different influence on travel intention, and risk perception and destination image are influenced by familiarity. All of them have effects on travel intention. The results of theoretical hypothesis answer how the risk perception and the image perception affect travel intention with familiarity.

(1)Impact of risk perception on travel intention. The empirical data after Jiuzhaigou earthquake shows that the results are basically consistent with the Li Yue model except for physical and health 
risks. The reason is that the disaster area of Jiuzhaigou is concentrated around the scenic spot. The victims are mainly tourists who visited the scenic spot at that time, so potential tourists will consider their physical safety more.

(2)The influence of destination image perception on travel intention. In the exploratory factor analysis of the destination image, four factors were separated out in this study. Compared with the Li Yue's model, it has an extra factor and name it the destination activities image. The results show that all the destination image perception has distinctly positive correlation with travel intention except facilities image perception. Due to the impact of serious natural disasters, the destination facilities image perception of tourists is reduced. However, this change is caused by force majeure and Jiuzhaigou is located in mountainous so that tourism facilities is not perfect, potential tourists are also acceptable to it and will not obviously affect their intention to travel.

(3)The influence of familiarity on tourism intention. Compared with the research model of Li Yue, the familiarity of Jiuzhaigou has no significant influence on travel intention. Therefore, the differences mainly consider the frequency of earthquakes in China, especially in Sichuan in recent years, and the popularity of Jiuzhaigou. Although most scholars' research shows that familiarity is positively related to tourism intention, MacKay and Fesenmaier pointed out in their research that the relationship between familiarity and attraction is bell-shaped curve, that is, the more familiar tourist destinations are, the more attractive they are before reaching a certain point[17]. Once the turning point is reached, the increase of familiarity will make the attraction of destinations gradually lose. Therefore, familiarity after Jiuzhaigou earthquake may have less influence on travel intention.

In practice, it is beneficial to the rapid recovery of the quake-hit areas in Jiuzhaigou. First of all, both government and tourism enterprises should pay attention to the impact of post-disaster risk perception on travel intention, The negative impact of financial risk and crime risk perception is propagated through various channels and media to publicize the recovery of scenic spots, with emphasis on the news related to security, good public order, and financial recovery. In addition, they also should focus on destination characteristics image perception, the management image perception and the activities image perception's positive influence, publicize scenic spots, various activities, and create a variety of food and beverage. Protect environment, provide shopping mall, unite local residents, strengthen the management of scenic spots.

\section{Inadequacies and prospects}

Firstly, most of the subjects who participated in the questionnaire were 18-25 years old, most of them had bachelor degree or above, and most of them were students. This made the sample unable to reflect the different kind of subjects to risk perception, destination image perception and familiarity, and travel intention. Later studies can examine this items' influence to the model.

Secondly, this study has not yet explored why different risk perceptions have different effects on travel intentions, and why different destination image perceptions have different effects on travel intentions. Therefore, we can explore the reasons in the later research.

\section{Summary}

Referencing Li Yue's influence factors on post-disaster travel intention model, this research analyses the relationship among risk perception, destination image, destination familiarity and tourists travel intention, which could reveal the tourists' psychological mechanism when they decide to travel in the disaster area. In this paper, there are eight tourist risk perception dimensions forming, which include physical risk, health risk, finance risk, social risk, moral risk, convenience risk, psychological risk, crime risk. This study identifies the importance of these eight factors of risk perception. Meanwhile, it's found that the tourists risk perception is useful to rebuild the destination image and tourists market recovery. In addition, the three dimensions of destination image perception are positively related to travel intention, indicating the importance of destination image perception on post-disaster travel intention. The influence of familiarity on risk perception identified in the study could provide helpful suggestions on easing worry of tourists. In summary, 
on the one hand this study identifies the feasibility of Li Yue's model to a certain degree, on the other hand the results that the study proposes is helpful for post-disaster destination to retain the confidence of travelers and the travel industry, and to minimize the impact of a crisis on the destination.

\section{Acknowledgements}

Supported by Young Tourism Expert Training Program of Sichuan Provincial Tourism Development Committee (SCTYETP to Yue Li); by Scientific Research Foundation for Returned Scholars, Sichuan Provincial Human Resources and Social Security Department (to Yue Li); by Soft Science Project of Science \& Technology Department of Sichuan Province (to Yue Li).

\section{References}

[1] S.M. Liu, J.F. Nan, W. Li: Journal of Hainan University (Humanities and Social Sciences Edition), Vol. 28 (2010) No.2, p.89-94.(In Chinese)

[2] Y. Li: Research on Effect Factors to Travel Intention after Severe Natural Disasters-Take tourist psychological perception after the Wenchuan earthquake for example (Ph.D., Sichuan University, China 2010), p.56.(In Chinese)

[3] S.B. Sitkin, L.R. Weingart: Academy of Management Journal, Vol. 38 (1995) No.6, p.1573-1592.

[4] C.F. Huang, A.L. Liu, Y. Wang: Journal of Natural Disasters, (2010) No.6, p.8-16.(In Chinese)

[5] Bauer, R. A. : Chicago: American Marketing Assiciation, (1960), p389-398.

[6] M. Grosspietsch: Tourism Management, Vol.27 (2006) NO.2, p225-234.

[7] Baloglu S: Journal of Travel and Tourism Marketing, Vol.8 (1999) NO.3, p81-90.

[8] D. O.Sears, J. L. Freedman, L.A. Peplau: Social Psychology (Fifth Edition) (Prentice-hill, INC., Englewood cliffs, N.J., Americian 1985).

[9] H. Maestro, O. Gallego: Journal of Travel Research. Vol.48 (2009) No.1, p58-77.

[10]X. Cheng, L. N. Sui: Tourism science, (2006) No.21, p7-12.(In Chinese)

[11] J. Gao, C. L. Xu, Y. X. Zhu:East China Economic Management. (2013) No.11, p.150-154.(In Chinese)

[12]U. Yavas:European journal of marketing. Vol.21 (1987) No.5, p.57-69.

[13]H. H. Yang, L. Wu, L.J. Zheng: Journal of Ningbo University (Educational Science Edition). (2008) No.1.(In Chinese)

[14]J. N. Goodrich: Journal of Travel Research. (1978) No.16, p8-13.

[15]A. G. Woodside, S. Lysonski: Journal of Travel Research. (1989) No.16, p8-14.

[16] J. Yang, P. Hu, B. H. Yuan: Tourism journal. (2009) No.4, p24.(In Chinese)

[17] K. J. MacKay, D. R. Fesenmaier: Journal of Travel and Tourism Marketing. Vol.7 (1998) No.3, p.1-18. 